\title{
PROXIMO-DISTAL INCREASE OF ENZYMIC ACTIVITY IN THE DORSAL SPINAL TRACTS*
}

\author{
Reinhard L. Friede and Mechthilde Knoller \\ Mental Health Research Institute and Department of Pathology \\ The University of Michigan, Ann Arbor, Michigan
}

(Received 6 April 1964)

IT Is known that enzyme distribution is not the same among various fibre tracts, but except for LUBLINSKA's (1962) report of a proximo-distal decrease of cholinesterase along peripheral nerves there is little information about differences of enzyme activity along the course of a given fibre tract. This paper presents biochemical and histochemical data of the distribution of lactate dehydrogenase (LDH) along the tractus gracilis (Goll's tract) and the tractus cuneatus (Burdach's tract). The enzymes cytochrome oxidase (CYO), succinate dehydrogenase (SDH), malate dehydrogenase (MDH), glutamate dehydrogenase (GDH), and glucose 6-phosphate dehydrogenase (G-6-PDH) were also studied histochemically. The data show a gradual proximodistal increase of most of these enzymes in the axons of both fibre tracts; however, the increase is much more pronounced in the tractus gracilis than in the tractus cuneatus. The possible significance of this phenomenon is discussed.

Additional studies evidenced an inverse distribution of $\mathrm{LDH}$ in glial cells and axons along the course of the tractus gracilis: in the caudal part of the tractus gracilis, the LDH activity was strong in many glial cells and weak in the axons; in the cranial-most part of the tract, there was no LDH activity in glial cells but it was very intense in the axons.

\section{MATERIAL AND METHODS}

Assay methods. Biochemical determinations of the LDH activity at different levels of the tractus gracilis and tractus cuneatus were made in ten cats; two cats were used for preliminary establishment of a standard procedure for sampling. The results of studies on eight cats are included in the biochemical data. The cats were sacrificed with sodium pentobarbitone and the medulla oblongata and $6 \mathrm{~cm}$ of the cervical spinal cord were removed. The tissue was transferred to ice-cold saline and used within $10 \mathrm{~min}$. Transverse dorso-ventral incisions were made into the cord to divide the dorsal tracts into segments exactly $5 \mathrm{~mm}$ in length. By comparing the features of the cross section of the cord with the dorsal fissure, sulci and roots at its dorsal surface, the positions of the tractus gracilis and cuneatus were readily determined, and wedge-shaped samples were cut from each tract from the dorsal surface of the cord. In the beginning, after the assay sample was removed the remainder of the specimen was fixed and embedded in paraffin, and the stained sections were studied to determine if assay samples were free of contamination by adjacent tissue. After a little practice, uncontaminated samples of both tracts were obtained without difficulty.

The wet weight of each sample, 2.5-7 mg, was determined immediately. These samples were transferred to chilled glass tissue-grinder tubes and homogenized with a motor driven pestle in ice-cold tris buffer, $\mathrm{pH} \mathrm{7.4}$. Concentration of homogenates was $10 \mathrm{mg}$ of tissue per $\mathrm{ml}$ of buffer. The incubation medium was slightly modified from that of ALLEN and SLATER (1961) for cytochemical determination of LDH: $1 \mathrm{ml}$ sodium lactate, $0.5 \mathrm{M} ; 1 \mathrm{ml} \mathrm{NAD}, 0.01 \mathrm{M} ; 1 \mathrm{ml}$ potassium cyanide,

* This investigation was supported by U.S. Public Health Grant B-3250.

Abbreviations used: CYO, cytochrome oxidase; GDH, glutamate dehydrogenase; G-6-PDH, glucose 6-phosphate dehydrogenase; INT, iodinitrotetrazolium; LDH, lactate dehydrogenase; MDH, malate dehydrogenase; Nitro BT, nitro-blue tetrazolium; SDH, succinate dehydrogenase. 
$0.6 \mathrm{M} ; 1 \mathrm{ml}$ disodium dihydrogen EDTA, $6 \mathrm{mg} / \mathrm{ml} ; 3 \mathrm{ml}$ phosphate buffer, $0.1 \mathrm{M}, \mathrm{pH} 7.5 ; 3 \mathrm{ml}$ iodinitrotetrazolium (INT), $1 \mathrm{mg} / \mathrm{ml}$. A final pH of 7.4 gave optimal results. To $3 \mathrm{ml}$ of medium at $38^{\circ}, 0.1 \mathrm{ml}$ of homogenate was added. Wherever possible, triplicate determinations were made (approximately 20 per cent of the determinations were done in duplicate). The mixture was incubated for $30 \mathrm{~min}$ in a constant temperature water-bath shaker at $38^{\circ}$, and the reaction stopped by addition of $0.5 \mathrm{ml}$ of TCA to each sample. The reaction product, INT-formazan, was extracted and photometrically measured as previously described (Friede, Fleming and KNoLler, 1963). No-substrate blanks and no-tissue blanks were included in each experiment. The blank measurements were subtracted from the measurements of the unknown samples. The enzyme concentration curve showed a straight line with tissue dilutions from $3 \cdot 0-0.5 \mathrm{mg}$ per sample. The time curve gave a straight line up to $25-30 \mathrm{~min}$ and levelled off slightly with longer incubation. We felt justified in using $30 \mathrm{~min}$ incubations since there was only a minimal, questionable, deviation from a straight line at this point, and a maximal yield was desirable because of the low activity present in these samples.

Materials. The tissue-grinder tubes were obtained from Kontes Glass Co; tris buffer and sodium lactate from Sigma Chemical Co., St. Louis, Missouri; NAD from California Corporation for Biochemical Research, Los Angeles, California; EDTA from the G. Frederick Smith Chemical Co., Columbus, Ohio, and INT from Dajac Laboratories, Philadelphia, Pennsylvania.

Histochemical methods: Medulla oblongata and about 5-8 segments of the cervical cord from ten cats, three dogs and nine rats were placed in cold $10 \%$ neutral formalin, fixed over night at $4^{\circ}$, and sectioned longitudinally at $30 \mu$. Alternate sections were incubated for LDH activity [the sections were incubated in the medium described above for the biochemical assays with Nitro BT substituted for INT]; the other sections were stained with chrome alum gallocyanin. Complete details regarding storage, fixation, cutting, and incubation procedures have been given previously (FrIEDE et al., 1963). In addition the following enzymes were studied in cats in $30 \mu$ sections of unfixed tissue: CYO (Burstone and Weisburger, 1961); SDH (Friede et al., 1963); MDH (Pearse, 1960); GDH (Pearse, 1960); G-6-PDH (Friede et al., 1963). Each enzyme was studied in two cats. All sections were dehydrated and mounted in permount.

Methods for glia cell counts: Longitudinal sections of the upper $6 \mathrm{~cm}$ of cat cervical cord were used. By marking the cover slip on mounted sections, the tractus gracilis was marked off into $5 \mathrm{~mm}$ segments, measured caudal from the obex. A square-ruled object micrometer with 100 squares was used for making cell counts in 10-12 fields within the $5 \mathrm{~mm}$ segments; the counts refer to a volume of $0.0053 \mathrm{~mm}^{3}$ tissue. In the gallocyanin-stained sections, all cells were counted except the endothelial cells. Some endothelial cells may have been mistakenly counted, but the extent of such error was considered equal at all levels of the tract. In LDH preparations, all glial cells that could be distinguished by a reaction in their cytoplasm were counted. Cells in blood vessel walls were not a source of error in the enzyme counts because the vessels were clearly distinguished by the distinct enzyme reaction in the basement membrane. The counts in Fig. 4 were not corrected for shrinkage. Dehydration produced approximately 5 per cent linear shrinkage of the tissue.

\section{RESULTS}

General distribution of LDH activity in the dorsal tracts. Biochemical data (Fig. 1) showed that the general pattern was the same for both tracts although the over-all enzyme level was higher in the tractus gracilis, and the enzyme activity increased more sharply. The proximo-distal increase of enzyme activity was gradual in the tractus gracilis until either 10 or $5 \mathrm{~mm}$ from the obex (caudal end of the 4th ventricle) at which point there was a very sharp increase in activity. Among cats, there was considerable variance in the amount of LDH activity in the tractus gracilis between 5 and $10 \mathrm{~mm}$ from the obex, whereas the activity at the same level in the tractus cuneatus was relatively the same in all cats studied (Fig. 1). In both tracts the LDH activity was highest toward the nucleus. Careful comparison of the biochemical findings with the microscopic studies of the histochemical preparations was made; the gradations of LDH activity along the tracts as determined by both methods were in excellent agreement (Fig. 2). Principal cytological and histochemical findings that explained the increase of enzyme activity in the cranial levels of the tracts were the islands of the nucleus gracilis which were located between fibre bundles in the cranial part of the tract; and the proximo-distal increase of enzyme activity in the axons and their swollen endings. 
Displaced islands of the nucleus gracilis. Small irregular-shaped islands of the nucleus gracilis lie between the fibres of the tractus gracilis in the upper cervical segments of the cat spinal cord. These have been described previously (FRIEDE, 1961a). Like all gray matter, these islands had very strong LDH activity. From 3-8 mm caudal to the obex there were large islands of the nucleus (Fig. 2); from 8-11 mm caudal the

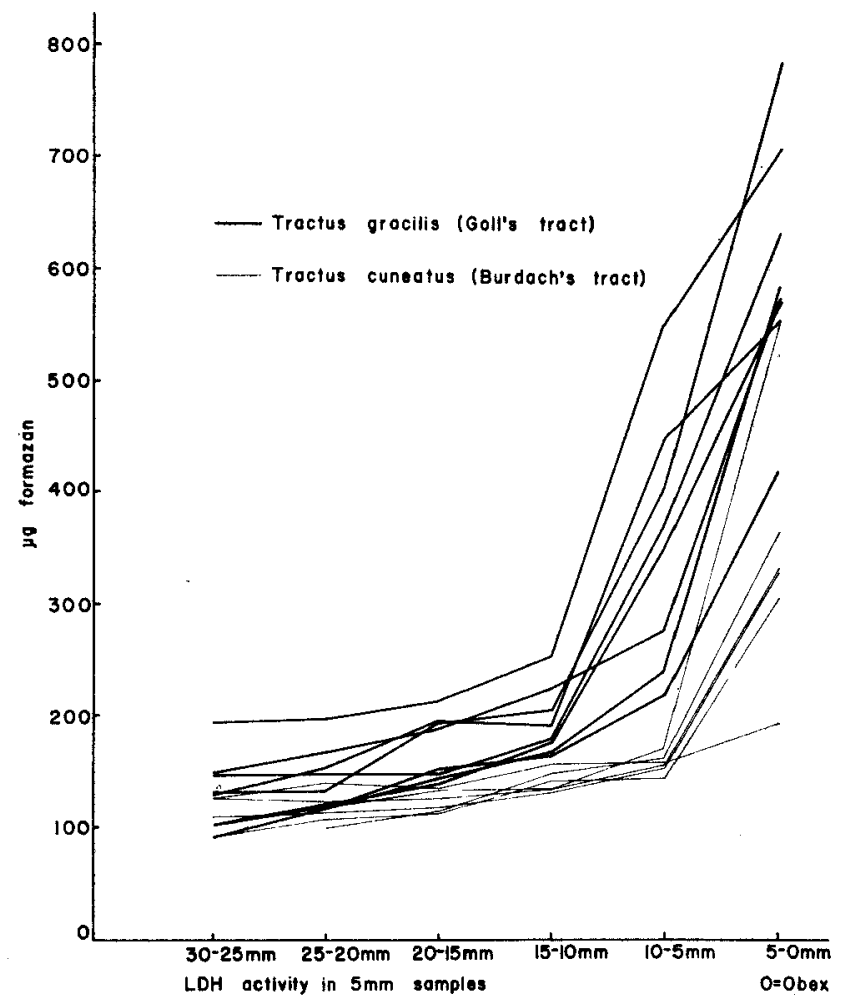

Fig. 1.-Biochemical assays of LDH in $5 \mathrm{~mm}$ samples of the tractus gracilis and tractus cuneatus of eight cats; each line represents measurements from one cat.

islands were smaller and fewer, and $11-15 \mathrm{~mm}$ caudal only occasional islands consisting of a few cells were seen. Such islands were more numerous in the ventral portion than in the dorsal portion of the tract; samples for biochemical assay were taken only from the dorsal portion. Displaced islands of nucleus gracilis were also seen in rats and dogs.

The maximal caudal extension of the cat nucleus cuneatus medialis varied from 3-14 mm from the obex. The nucleus cuneatus lateralis of cats was usually located cranial to the obex. There were no islands of gray matter located outside of the nucleus cuneatus itself except for rare groups of a few cells which were observed immediately adjacent to the nucleus.

Proximo-distal increase of $\mathrm{LDH}$ activity in axons. The study of longitudinal sections of cat cord showed only slight axonal LDH activity $20-30 \mathrm{~mm}$ caudal to the obex, and, in this region, no difference in the intensity of enzyme reaction could be distinguished between the two tracts. In the cranial direction, progressive proximo-distal 
increase was observed in both tracts, but there was a stronger enzyme reaction in the tractus gracilis than in the tractus cuneatus (Fig. 2). With the increase in enzyme activity, the axons appeared sharply outlined in longitudinal sections (Fig. 3B; 5A), exhibiting a gradual proximo-distal increase of staining. In transverse sections, the reaction was localized in the axon cylinders which were clearly distinguishable from the unstained myelin sheaths.

LDH activity in swollen terminal portions of axons. Studies by Newberne, ROBINSON, ESTEL and BRINKMAN (1960) showed that there are numerous swollen axons in the nucleus and tractus gracilis of normal dogs. In the present material, such swellings were found in dogs, rats and cats; they were more frequent in dogs and rats than in cats. All swellings had an intense staining with the $\mathrm{LDH}$ reaction (Fig. 3B). In accordance with the general increase of enzyme in axons along the tractus gracilis, the number of swollen axons increased in a proximo-distal direction along the tract. Swollen axons were not seen in the proximal portion of the tract where there was very little enzyme activity; they were seen only in that portion of the tract where enzyme activity was much increased (Fig. 3A); in cats, they were found only in the distal $15 \mathrm{~mm}$ of the tract. It was often possible to trace a gradual proximodistal increase of the enzyme activity along a given axon which suddenly showed marked distension, bulging, and club-shaped ending. Most swollen axons were headed in a cranial direction; only a few of the swollen axons were not headed in a cranial direction and they probably were recurrent axons, directed toward the displaced islands of the nucleus. In the nucleus and tractus cuneatus, very few, if any, axon swelling were observed (Fig. 3A).

Inverse correlation of axonal and glial LDH in the dorsal tracts. The gradual proximo-distal increase of $\mathrm{LDH}$ in the axons of the dorsal tracts was inversely related to the staining of the interfascicular oligodendroglia. Numerous oligodendroglia cells with LDH activity were seen in the caudal parts of the tracts, but their number decreased notably in the cranial parts where the axonal enzyme activity was higher. An effort was made to document these changes by cell counts in the feline tractus gracilis.

Glial cell counts in the gallocyanin-stained sections were relatively constant throughout the tractus gracilis.* Comparison with alternate sections that had been incubated for LDH activity revealed that, in the proximal portion of the tract, about a quarter of the total glial cell population showed LDH activity ranging from intense to minimal (Fig. 4). Axons in the same area exhibited very little LDH activity. Proximo-distally 20-5 mm from the obex, the number of glial cells with LDH activity gradually decreased (Fig. 4) while the activity in the axons increased (Fig. 5). Within $5 \mathrm{~mm}$ of the obex it was very rare to see glial cells with $\mathrm{LDH}$ activity (Fig. 3B, 5A); and those which were seen had very little activity; this represented a decrease in activity in the glial cells since the total glial cell count did not change. On the other hand, LDH activity was intense in all axons in this area. A similar pattern was noted in the distal portion of the tractus cuneatus, but both the axonal and glial changes were less extensive than those in the tractus gracilis.

* In the cranial-most $5 \mathrm{~mm}$ segment, the glial cell count was made on only one cat in gallocyaninstained sections and the result was in agreement with the average counts in the other segments of the tract. Glial cell counts were not made in this area on the other cats because of difficulties presented by the many islands of nucleus gracilis neuropil, which were not as readily distinguishable from white matter as they were in enzyme histochemical preparations. 


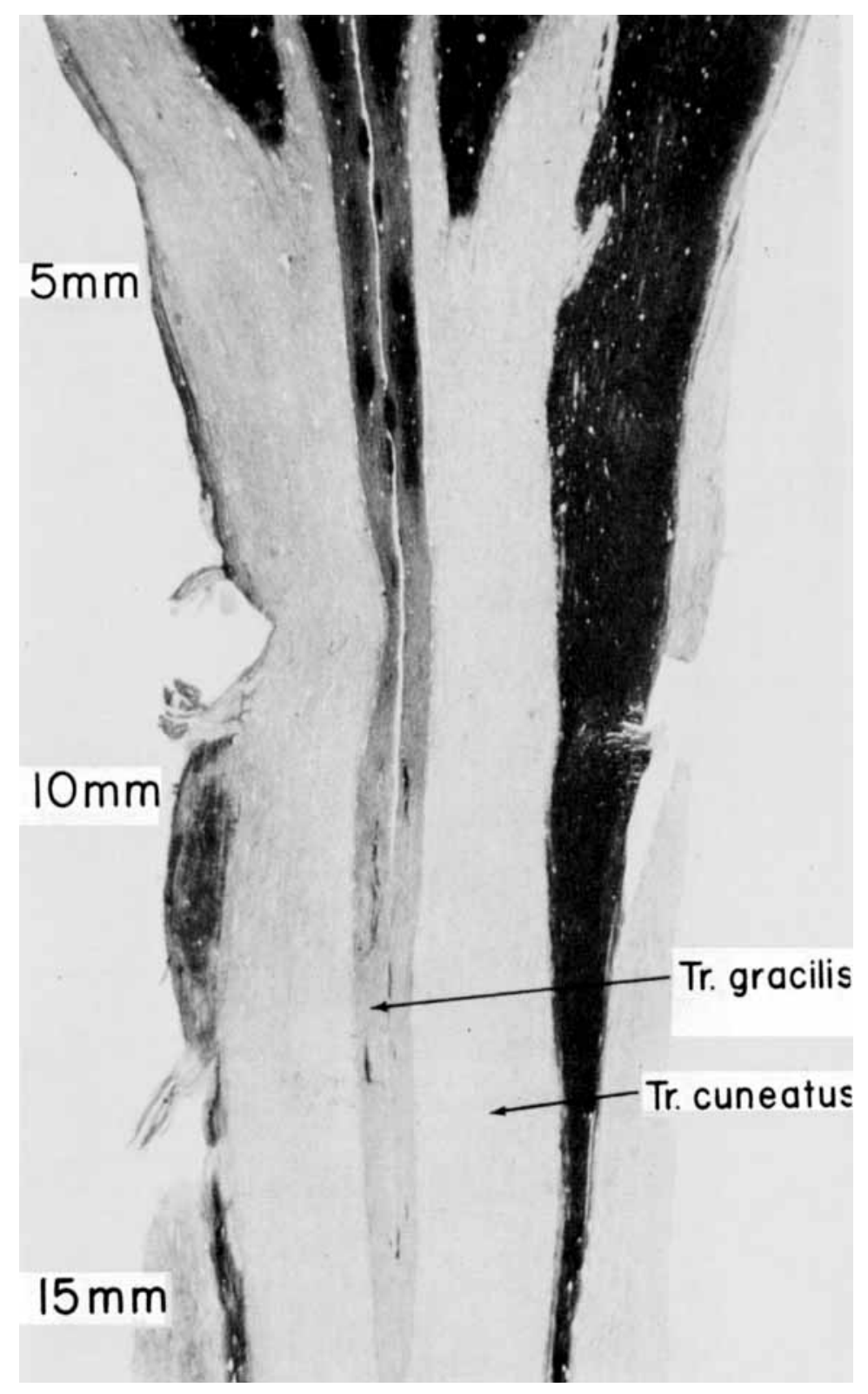

FIG. 2.-LDH activity in a $30 \mu$ longitudinal section of cat cervical cord. This section represents a plane parallel to the canalis centralis at a level touching the insertion of the dorsal roots on both sides. Some rootlets are visible on the left. The dark columns on the right (and some islands on the left) represent tangential cuts of the dorsal gray columns. Caudal extensions of the nucleus cuneatus medialis are seen on top. The fissura medianus dorsalis runs as a narrow slit along the median of the section. (The level is similar to Fig. 4A, but represents a smaller field). The marks on the left indicate the distance from the obex. $(17 \times)$ 


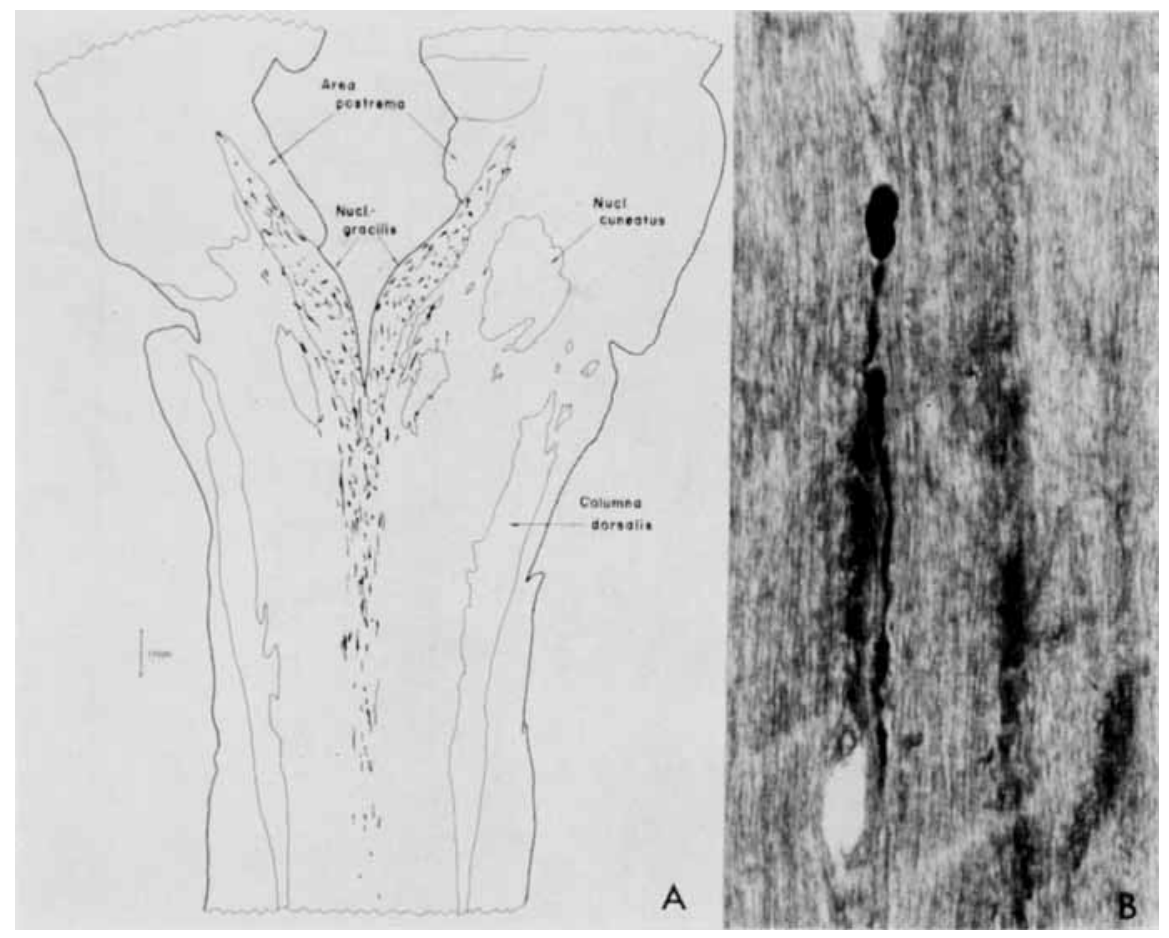

FIG. 3A.-A camera-lucida drawing of the distribution of swollen axons demonstrated by $\mathrm{LDH}$ activity in a $30 \mu$ section of the cervical cord of an adult dog. (This represents a sample where swellings were particularly numerous, but their distribution is representative of that observed in all three species studied.)

B. Marked LDH activity in axons and excessive LDH activity in two swollen axons in the cranial portion of the cat tractus gracilis. Note the absence of glia cells. $(320 \times)$ 

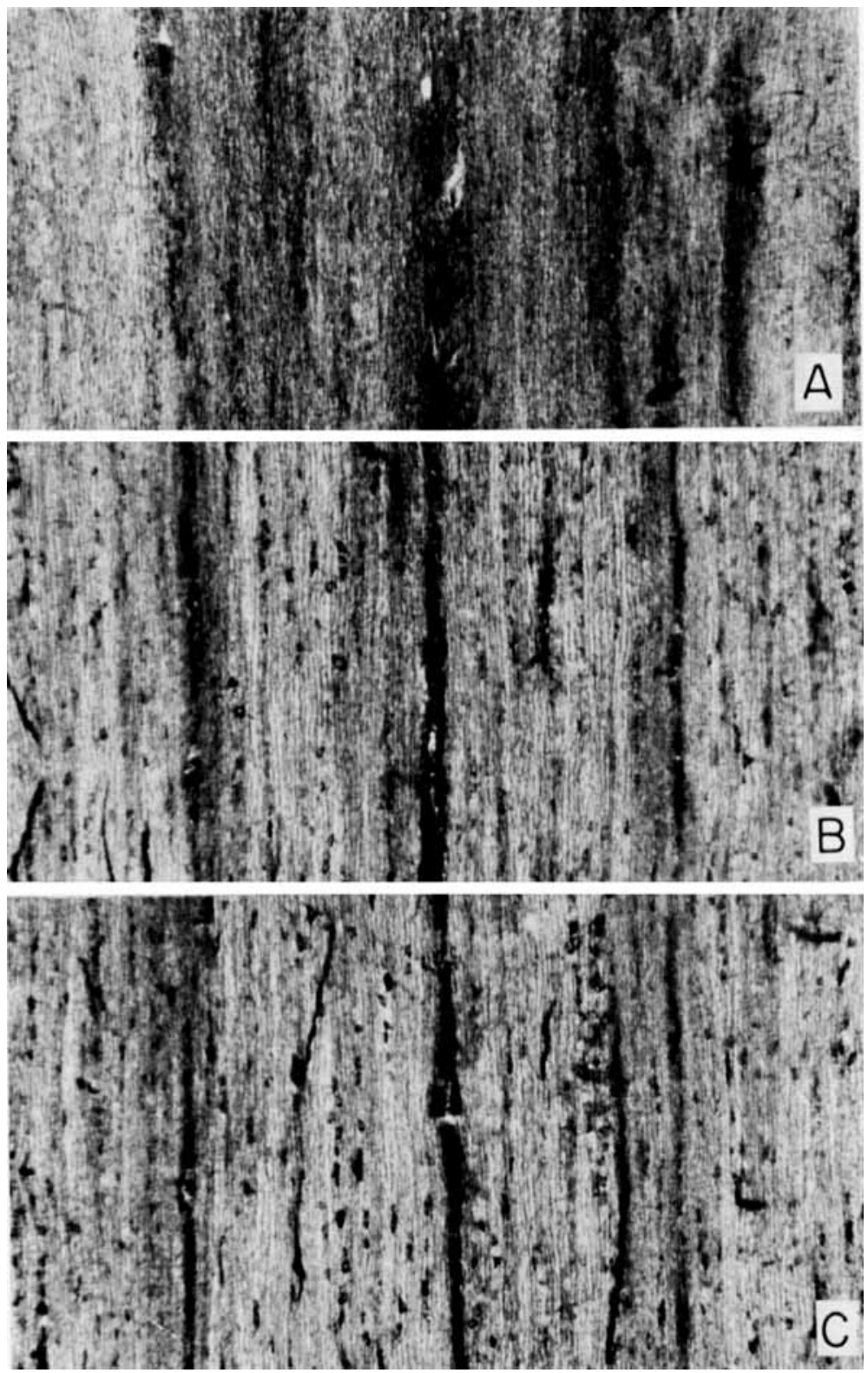

FIG. 5.-Distribution of LDH in three fields taken from the same section of the tractus gracilis. A: within $5 \mathrm{~mm}$ from obex; intense enzyme reaction in axons, very few, if any, glial cells discernible. $B$ and $C$ : gradual decrease of axonal enzyme activity paralleled by increased enzyme activity of glial cells. $(150 \times)$ 

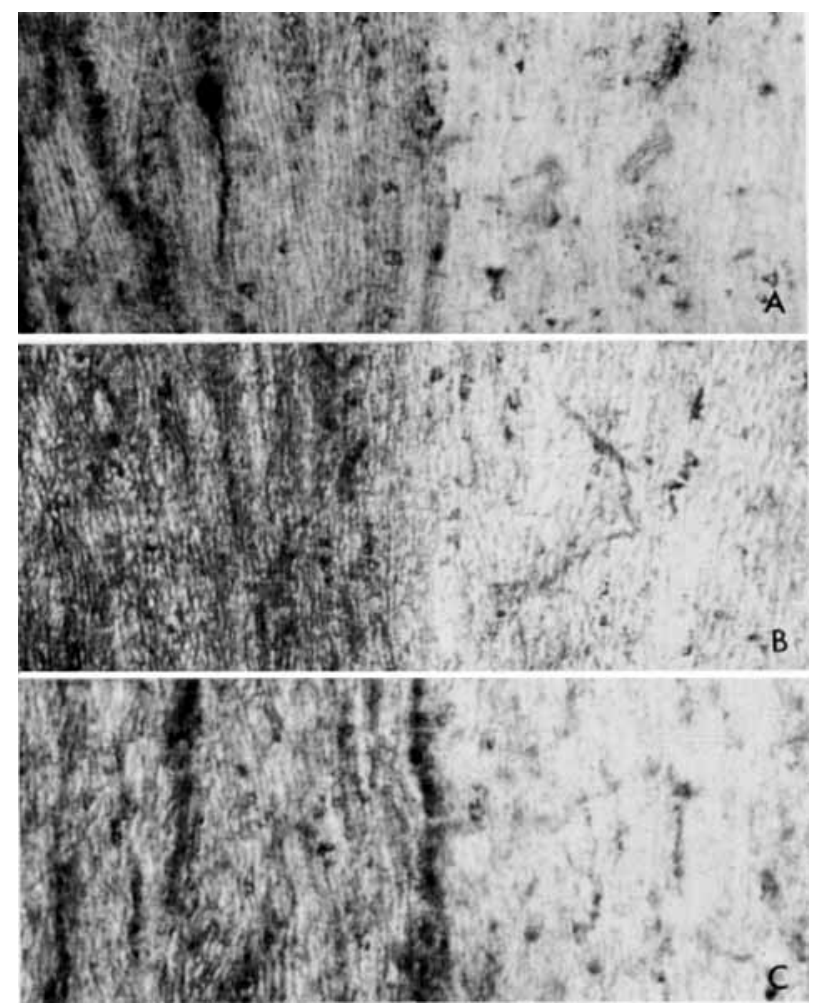

FrG. 6.-Comparison between the intense enzymic activity in the axons of the tractus gracilis (left) and the low activity in the axons of the tractus cuneatus (right) of the cat. (A) succinate dehydrogenase; (B) glucose 6-phosphate dehydrogenase; (C) malate dehydrogenase. All three pictures were taken from the upper $6 \mathrm{~mm}$ of cervical cord $(180 \times)$ 
Comparative histochemical studies. In addition to the LDH studies, SDH, MDH, G-6-PDH, CYO and GDH were studied in feline spinal cords. In the axons, the distribution of MDH (Fig. 6C) and G-6-PDH (Fig. 6B) was very similar to that of LDH (Fig. 5A) and a clear-cut proximo-distal increase of axonal enzymic activity was seen. The reaction for SDH was too weak to distinguish axons in the caudal portions

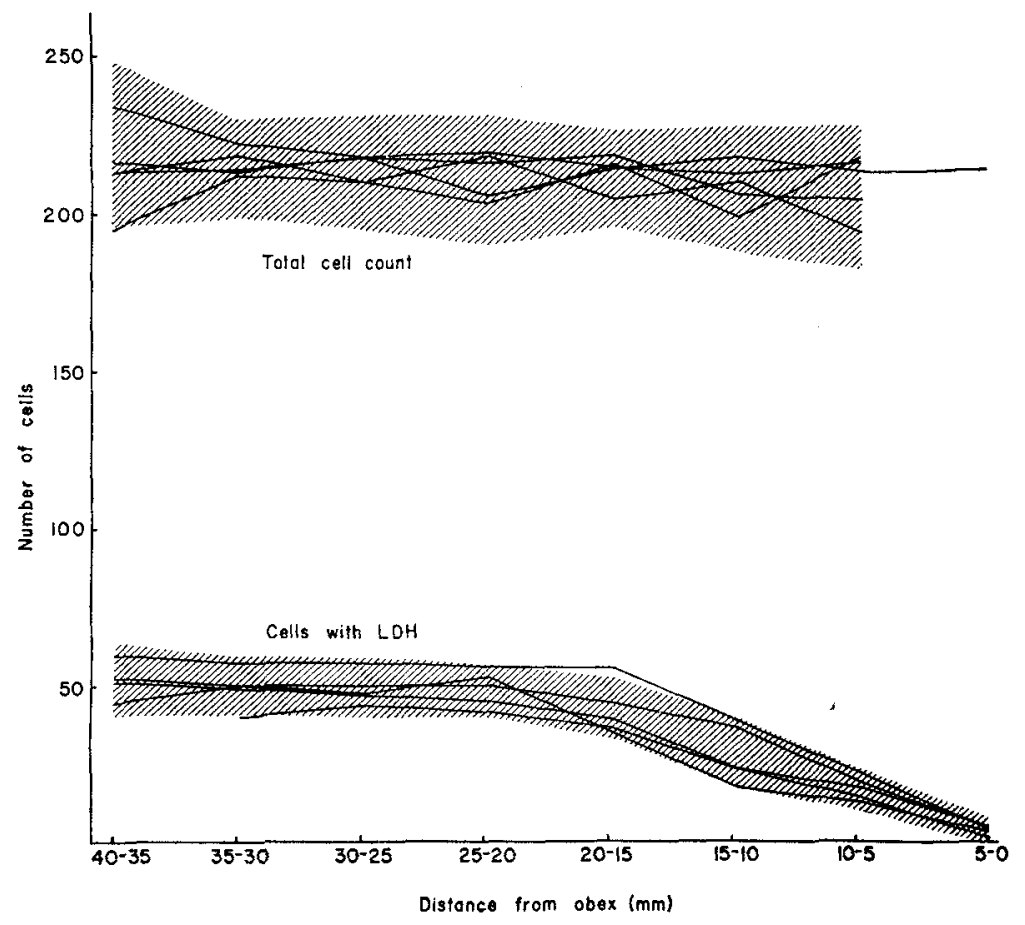

FIG. 4.-Cell counts of consecutive segments of the tractus gracilis of five cats*. The individual lines represent the mean values for each cat. The shaded area indicates the standard deviation of all counts. For further information see Material and Methods.

of the tracts, while those in the cranial part of the tractus gracilis were clearly stained (Fig. 6A). A very slight, diffuse increase of the CYO reaction was observed in the terminal portion of the tractus gracilis, but it was too weak to permit distinction of cellular details. All of these enzymes showed more activity in the terminal portion of the tractus gracilis than in that of the tractus cuneatus. Only for GDH was no clearcut indication of an increase of axonal staining seen in either tract.

The inverse distribution of axonal and glial enzyme activity was most pronounced for LDH, although the pattern was similar for NAD-diaphorase, G-6-PDH, and MDH. The SDH activity pattern was also similar but a few glial cells with moderate activity were observed even in the cranial-most part of the tracts. The GDH activity was intense in glial cells and minimal in axons throughout the tracts.

\footnotetext{
* see footnote to p. 682 .
} 


\section{DISCUSSION}

Other enzyme histochemical studies that have been reported for the tractus gracilis are: G-6-PDH (Thomas and PeArSe, 1961); SDH (FrIede, 1961a); and DPNdiaphorase (FrIEDE, 1961b). The first description of axon swelling in the nucleus gracilis of normal dogs was reported by Newberne et al. (1960). Pentschew and SchWARz (1962) reported excessive axon swelling in several nuclei of brain and cord of vitamin E-deficient rats, whereas in their normal control rats axonal swellings were observed only in the nucleus gracilis. Electron microscopical studies by LAMPERT, Blumberg and Pentschew (1964) indicated that the swelling often involved the immediate presynaptic portion of the axons.

The present study has demonstrated the importance of having a knowledge of the chemo- and cytoarchitecture at all levels of the tractus gracilis and tractus cuneatus for the interpretation of the biochemical measurements of LDH activity at different levels in the tracts. As has been described, the cranial part of the tractus gracilis always contains a varying amount of gray matter from islands of the nucleus gracilis. Also, the activity in axons varies along the dorsal tracts. After an understanding of the complex chemo- and cytoarchitecture of the tractus gracilis is reached, variations in reports on the chemistry of this tract are not surprising. For example: the data of BRECKENRIDGE and CRAWFORD (1961) showed good correlation among several regions of the rabbit brain in the gradation of four enzymes concerned with glycogen metabolism, but the dorsal tract data did not agree; ROBINS, ROBERTS, EYDT, LOWRY and SMITH (1956) commented on what they considered to be species difference among tracts of monkey and rabbit; a comparison of their data with those of STROMINGER and Lowry (1955) indicated that the dorsal tracts in monkey had about 50 per cent less $\mathrm{MDH}$ but 50 per cent more $\mathrm{LDH}$ than in rabbit. Also, MCDougal, Schulz, Passonnead, Clark, Reynolds and Lowry (1958, 1961) and Robins (1960) reported exceptional variation in the ratio of G-6-PDH to 6-phosphogluconic dehydrogenase in the dorsal tracts and the dorsal spinocerebellar tracts, as compared with other tracts. Unless the patterns of chemo- and cytoarchitecture are known, general conclusions regarding the metabolism of whole fibre tracts should be considered with reservation.

Two hypotheses regarding the cause of the phenomenon of the proximo-distal increase of enzyme activity in axons and their swellings may be considered: 1) enzyme synthesis may occur in the presynaptic portion of the axons and result in excessive accumulation of axoplasm there; 2) axonal swellings may represent an excess of enzymically active axoplasm resulting from a proximal to distal convection that exceeded the rate of utilization and/or decay of the axoplasm or some of the constituents therein. We feel that the proximo-distal increase of enzyme activity along the course of a fibre tract might be a universal phenomenon, which, because it is usually slight, has escaped attention so far. Such slight changes were observed by us in the tractus cuneatus and along axons in fibres entering the dorsal spinal columns. On the other hand, the extent to which this phenomenon occurs in the tractus gracilis may be unequalled elsewhere in the nervous system. We have not observed anything comparable in previous work of mapping enzymes in normal brain (FRIEDE, 1961 $a, b$; FRIEDE and Fleming, 1962; 1963). Further experiments are needed to help elucidate the mechanism by which this phenomenon occurs and what its significance may be. It 
looks as though the tractus gracilis could be an ideal 'model' for a variety of experiments to study the convection of axoplasm along an axon.

The additional observations on reciprocity of axonal and glial LDH suggest an interdependence of glial and axonal enzyme supply. The distribution of NAD-diaphorase in various human fibre tracts varied in a similar manner: in tracts with intense enzyme activity in the axons, most glial cells had no enzyme activity; whereas, in tracts with relatively little axonal enzyme activity, many of the glia cells had strong enzyme activity (FrIEDE, 1961 b). These observations suggest that both axons and glia cells contribute to the metabolic maintenance of the nerve fibre and that the contribution of each is rather specific in a given fibre tract but varies considerably among fibre tracts. In the present studies, it was of particular interest that the distribution of LDH in axons and glial cells varied inversely within the course of one fibre tract. This strongly implies that the activity of the interfascicular glial cells depends upon, and can adjust to, the local needs of the axons. Such a concept is in keeping with CAJAL's (1928) theory of symbiosis of axon and fascicular glia and the theory that glial cells can function as 'auxiliary metabolic units' which attach to the nerve cells whenever special metabolic needs arise (FRIEDE and VAN HOUTEN, 1962).

\section{SUMMARY}

The distribution of lactate dehydrogenase ( $\mathrm{LDH})$ activity in the tractus gracilis and tractus cuneatus was studied in normal cat, dog and rat. Biochemical and histochemical studies in cats showed that there is a gradual proximo-distal increase of the enzyme in the axons of both tracts, although it is much more extreme in the tractus gracilis. There was marked increase of enzyme activity in the distal portions of the axons, and many swollen axons with intense activity were present in the tractus and nucleus gracilis. A similar distribution of activity was observed for several other oxidative enzymes. The significance of chemo- and cytoarchitectural knowledge for the interpretation of microchemical assays of fibre tracts is discussed.

Additional histochemical studies and cell counts evidenced a reciprocal relation between the proximo-distal increase of LDH in axons and a proximo-distal decrease of glial cell LDH activity. The inverse distribution of enzyme activity strongly implied that there is a symbiotic interdependence between axonal and glial cell enzyme activity.

\section{REFERENCES}

Allen J. M. and Slater J. J. (1961) J. Histochem. Cytochem. 9, 221.

Breckenridge B. M. and Crawford E. J. (1961) J. Neurochem. 7, 234.

Burstone M. S. and Weisburger E. K. (1961) J. Histochem. Cytochem. 9, 59.

CAJAL S. R. (1928) Degeneration and Regeneration of the Nervous System. Milford, London.

FrIEDE R. L. (1961a) A Histochemical Atlas of Tissue Oxidation in the Brain Stem of the Cat. S. Karger, Basel and New York.

FRIEDE R. L. (1961b) J. Neurochem. 8, 17.

FRIEDE R. L. and Fleming L. M. (1962) J. Neurochem. 9, 179.

Friede R. L. and Fleming L. M. (1963) Amer. J. Anat. 113, 215.

Friede R. L., Fleming L. M. and Knoller M. (1963) J. Histochem. Cytochem. 11, 231.

Friede R. L. and van Houten W. H. (1962) Proc. nat. Acad. Sci. (Wash.) 48, 817.

Lampert P., Blumberg J, and Pentschew A. (1964) J. Neuropath. exp. Neurol. 23, 60.

LUBLINSKA L. (1962) Science 135, 368.

MCDougal D. B. (1958) Neurology (Minneap.) 8, 58.

McDougal D. B., Shulz D. W., Passonneau J. V., Clark J. R., Reynolds M. A. and Lowry O. H. (1961) J.gen. Physiol. 44, 487. 
Newberne J. W., Robinson V. B., Estel L. and Brinkman D. C. (1960) Amer. J. Vet. Res. $21,782$. Pearse A. G. E. (1960) Histochemistry. Little, Brown and Co., Boston. Pentschew A. and Schwarz K. (1962) Acta. neuropath. (Berl.) 1, 313. Robins E. (1960) J. Histochem. Cytochem. 8, 431.

Robins E., Roberts N. R., Eydt D. M., Lowry O. H. and Smith D. E. (1956) J. biol. Chem. $218,897$. Strominger J. L. and Lowry O. H. (1955) J. biol. Chem. 213, 635.

Thomas K. C. and Pearse A. G. E. (1961) Histochem. 2, 266. 